Vol. 1 No. 2, Juni 2021, hlm. $147-152$

DOI: https://doi.org/10.33330/jutsi.v2i1.1161

Available online at http://jurnal.stmikroyal.ac.id/index.php/jutsi

\title{
ANALISA SISTEM INFORMASI STOCK CONTROLLING SEPATU DENGAN MENGGUNAKAN METODE BACK ORDER
}

\author{
Yogi Pratama ${ }^{1}$, Iqbal Kamil Siregar ${ }^{2^{*}}$, Dewi Maharani ${ }^{3}$ \\ ${ }^{1}$ Mahasiswa Prodi Sistem Informasi, STMIK Royal \\ ${ }^{2}$ Prodi Sistem Komputer, STMIK Royal \\ ${ }^{3}$ Prodi Manajemen Informatika, STMIK Royal \\ *email: iqbalkamilsiregar@royal.ac.id
}

\begin{abstract}
The development of computer science as a human tool, especially in data processing media and the excellence factor of the computer itself which can be in the form of technological advances in information. With that we will produce goals information that is fast and precise so that it helps in making decisions in processing data items, both goods in and out of the process of buying and selling goods. Store shoes Abang Adik is a business that is engaged in the sale of shoes and this shop has many obstacles in the report and the use of computers that are not maximal. In this case the back order method can be used to solve the problem so as to avoid store losses. With this method the back order method functions as if the goods in the warehouse are running low then the seller will know and will directly order the goods to the supplier to add to the stock of empty goods. With the system of controlling goods using the back order method can prevent the shortage of goods in the store shoes Abang Adik and the calculation of inventory costs more accurately.
\end{abstract}

Keyword: Stock Controlling; Visual Basic; Back Order Method.

\begin{abstract}
Abstrak: Perkembangan terhadap ilmu komputer sebagai alat bantu manusia khususnya dalam media pengolahan data dan faktor keunggulan dari komputer itu sendiri yang dapat berupa kemajuan teknologi dibidang informasi. Dengan hal itu kita akan menghasilkan tujuan informasi yang cepat dan tepat sehingga membantu dalam membuat keputusan dalam mengolah data barang, baik barang yang masuk dan keluar pada proses pembelian maupun penjualan barangbarang. Toko Abang Adik Shoes merupakan usaha yang bergerak di bidang penjualan sepatu dan toko ini ada banyak kendala dalam laporan serta penggunaan komputer yang kurang maksismal. Dalam hal ini metode back order dapat digunakan untuk memecahkan masalah tersebut sehingga tehindar dari kerugian toko. Dengan hal ini metode back order berfungsi sebagai apabila barang yang berada digudang menipis maka penjual akan tahu dan secara langsung akan memesan barang kepada supplier untuk menambah stok barang yang kosong. Dengan adanya sistem pengontrolan barang dengan metode back order dapat mencegah terjadinya kekurangan stock barang pada Toko Abang Adik Shoes dan perhitungan biaya-biaya persediaan lebih akurat.
\end{abstract}

Kata Kunci: Stock Controlling; Visual Basic; Metode Back Order. 
Vol. 1 No. 2, Juni 2021, hlm. $147-152$

DOI: https://doi.org/10.33330/jutsi.v2i1.1161

Available online at http://jurnal.stmikroyal.ac.id/index.php/jutsi

\section{PENDAHULUAN}

Perusahaan kecil maupun besar seperti perusahaan dagang, industri atau jasa selalu melakukan persediaan. Persediaan atau stok barang sangat penting untuk diperhatikan dalam menjalankan sebuah perusahaan [1]. Ketika suatu perusahaan mengalami kelebihan stok barang tentunya akan merugikan perusahaan itu sendiri dikarenakan rotasi keuangan yang tidak berjalan semestinya atau muncul biaya tambahan terhadap modal. Dan jika perusahaan kekurangan stok persediaan juga akan mengalami kerugian, disamping itu tidak bisa mencukupi keinginan klien secara baik juga akan membuat pelanggan atau konsumen berpindah ke pihak perusahaan lain [2].

Perkembangan terhadap ilmu komputer saat ini sebagai alat bantu manusia khususnya dalam media pengolahan data, baik berskala besar maupun berskala kecil, sekarang ini mengalami pengembangan positif yang sangat pesat. Kondisi ini terkontributif terhadap aspek penganjur serta aspek supremasi terhadap komputer independen yang dapat berwujud pertumbuhan teknologi di sektor data, dan keperluan serta ketentuan khalayak yang menghendaki seluruh profesi serta keperluannya bisa dilangsungkan secara pasti, cekatan serta akurat.

Toko Abang Adik Shoes merupakan suatu usaha yang bergerak di bidang penjualan sepatu yang beralamat di kabupaten Asahan, dimana jumlah penjualan sepatu pada 3 tahun terakhir sejak 2016 sampai 2019 jika di rata-ratakan sekitar kurang lebih 2.500 pasang sepatu. Toko Abang Adik Shoes adalah usaha yang masih menggunakan pencatatan buku pada transaksi, laporan, dan permintaan barang yang dilakukan setiap hari. Dengan demikian, data barang yang dibuat kurang akurat dan lambat sehingga mengakibatkan terjadi tingkat kesalahan dalam melakukan transaksi data barang, laporan dan permintaan barang. Usaha ini memiliki peluang yang besar dan usaha ini memerlukan perkembangan dalam melakukan transaksi. Dengan seiringnya perkembangan teknologi, perlu adanya sebuah cara atau metode yang bisa diterapkan pada pengendalian persediaan. Salah satu metode yang bisa diterapkan ialah metode pengendalian persediaan back order.

Back order adalah suatu istilah terhadap pendistribusian barang dimana barang yang diminta belum bisa dipenuhi maupun semuanya maupun separuhnya [3]. Sebutan itu populer digunakan pada perbisnisan terutama terhadap pemasaran serta investasi produk via kiriman. Penggunaan kondisi back order adalah untuk menentukan jumlah persediaan barang yang habis ketika adanya permintaan dari konsumen yang tidak dapat dipenuhi atau dimana konsumen berhak memilih untuk menunggu pesanan dapat dipenuhi lagi atau sebaliknya.

\section{METODE}

Metode penelitian yang digunakan dalam penelitian ini adalah metode kualitatif. Metode kualitatif dilakukan dengan penelitian lapangan, penelitian perpustakaan, serta penelitian laboratorium. Penelitian lapangan dilakukan dengan pengamatan langsung ke Toko Abang Adik Shoes Kisaran, sehingga mendapatkan informasi terkait tentang sistem yang ada di Toko dan informasi data produk yang dijual. Penelitian yang dilakukan yaitu dengan pengambilan data-data yang diperlukan ditempat penelitian. 
Vol. 1 No. 2, Juni 2021, hlm. $147-152$

DOI: https://doi.org/10.33330/jutsi.v2i1.1161

Available online at http://jurnal.stmikroyal.ac.id/index.php/jutsi

Tabel 1. Data Barang

\begin{tabular}{|c|l|c|c|}
\hline No & \multicolumn{1}{|c|}{ Nama Barang } & Jumlah & Harga/Pasang \\
\hline 1. & Original Sepatu Bunut Enso & 20 & Rp.300.000 \\
\hline 2. & Carvil Wilson & 10 & Rp.250.000 \\
\hline 3. & Nike (Sport) & 25 & Rp.350.000 \\
\hline 4. & Bally Pantofel & 20 & Rp.400.000 \\
\hline 5. & Bata Comfit & 15 & Rp.470.000 \\
\hline 6. & Fila Clips & 12 & Rp.459.000 \\
\hline 7. & Penny Loafers & 8 & Rp.490.000 \\
\hline 8. & Oxford Shoes & 15 & Rp.350.0000 \\
\hline 9. & Wingtip Shoes & 10 & Rp.195.000 \\
\hline 10. & Pantofel Derby Shoes & 5 & Rp.949.000 \\
\hline 11. & Moc Toe Boots & & \\
\hline
\end{tabular}

Perhitungan stock controlling rancangan back order ialah dengan rumus sebagai berikut :

$$
\begin{aligned}
\text { Back Order } & =\sqrt{\frac{2 \cdot A \cdot D}{h}} \\
& \text { Di mana : } \\
D & =\text { Jumlah permintaan (Kebutuhan) } \\
h & =\text { Biaya simpan } \\
A & =\text { Biaya pesan }[4] \\
& : \sqrt{\frac{2 \cdot A \cdot D}{h}} \text { atau } \sqrt{\frac{2 \text { x biaya pesan } \mathrm{x} \text { kebutuhan }}{\text { biaya simpan }}}
\end{aligned}
$$

\section{HASIL DAN PEMBAHASAN}

Setelah melalui tahap perancangan, maka sistem yang dibangun telah berhasil menghasilkan sistem yang diperlukan. Sebelum memasuki menu utama kita awalnya akan sampai di dalam form login agar sistem terjaga keamanannya. Adapun login tersebut harus mengisikan nama user atau username serta mengisikan password yang telah disediakan oleh administrator.

Selanjutnya Form Menu Utama, ini berfungsi untuk mengontrol semua form yang ada, dari menu utama ini di panggil sub-sub menu program yang lebih kecil karena menu utama berfungsi sebagai program pengumpulan dari sekian banyaknya menu. Berikut form halaman Menu Utama dapat dilihat pada gambar 1. 
Vol. 1 No. 2, Juni 2021, hlm. $147-152$

DOI: https://doi.org/10.33330/jutsi.v2i1.1161

Available online at http://jurnal.stmikroyal.ac.id/index.php/jutsi

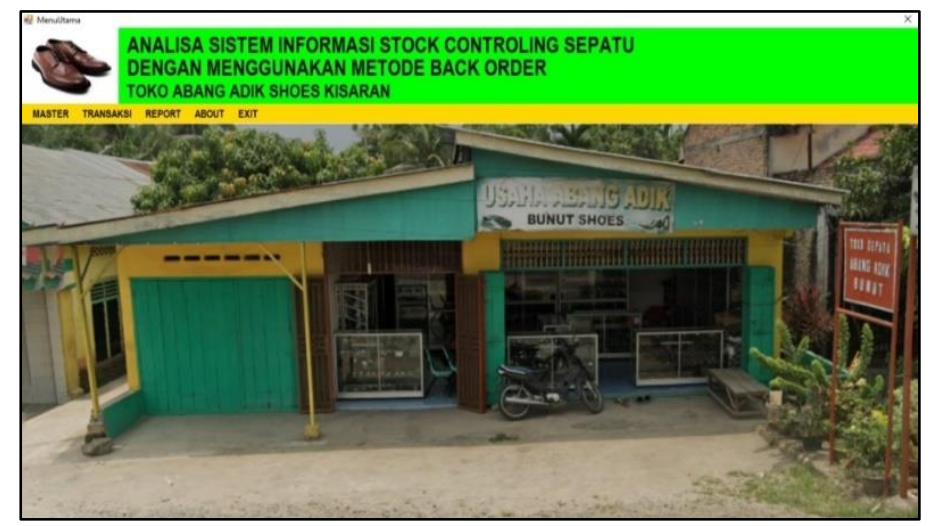

Gambar 1. Form Menu Utama

Selanjutnya form data penjualan, yaitu pada form ini admin selaku yang bertanggung jawab akan menginputkan data penjualan barang yang diminta oleh pelanggan. Form ini juga menampilkan data stok barang yang tersisa pada Toko Abang Adik Shoes, sehingga jika stok barang tidak mencukupi maka proses tidak bisa dilakukan. Form data penjualan terlihat pada gambar 2.

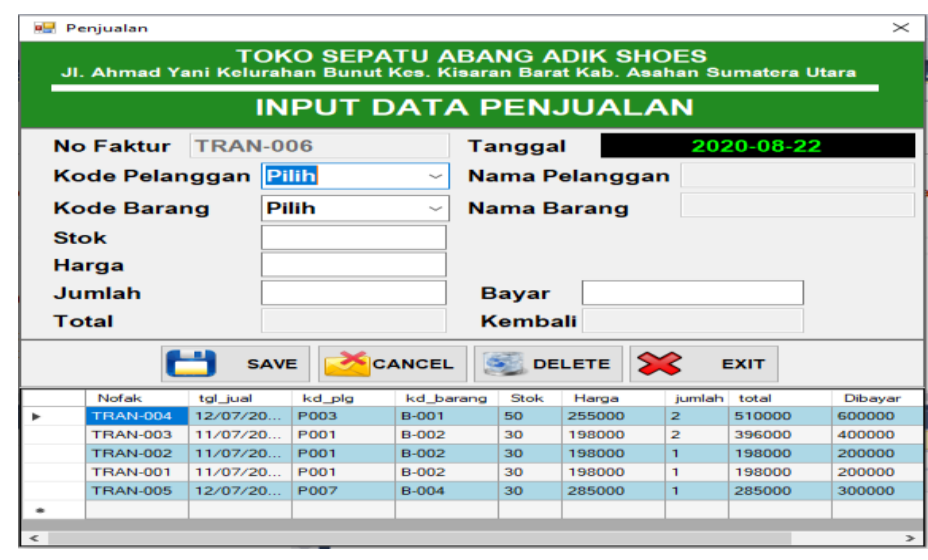

Gambar 2. Form Data Penjualan

Selanjutnya pada form back order, ini berfungsi sebagai menginput data back order ke dalam sistem untuk di simpan ke database, form back order dilihat seperti gambar 3.

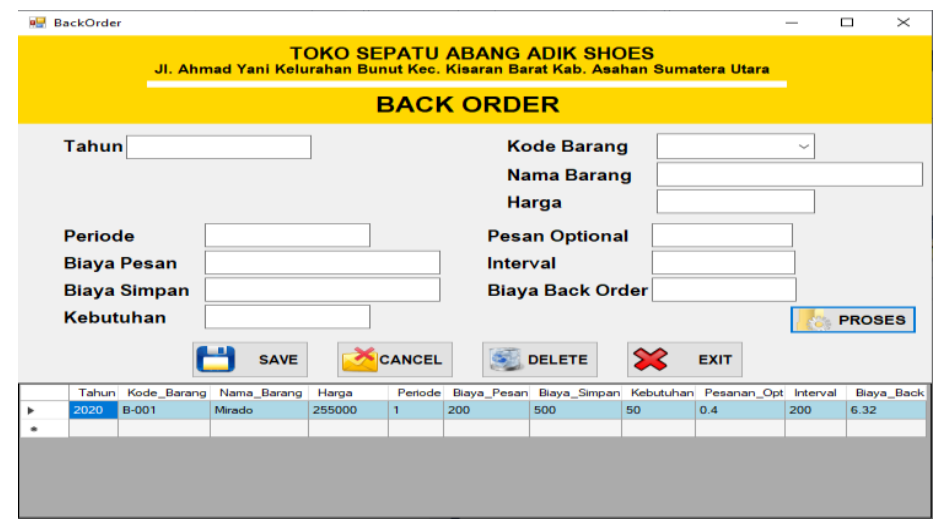

Gambar 3. Form Data Back Order 
Vol. 1 No. 2, Juni 2021, hlm. $147-152$

DOI: https://doi.org/10.33330/jutsi.v2i1.1161

Available online at http://jurnal.stmikroyal.ac.id/index.php/jutsi

Selanjutnya laporan data faktur penjualan, laporan penjualan ini ditampilkan pada data pembelian oleh pelanggan dan selanjutnya dicetak sebagai laporan penjualan kepada pimpinan. Laporan dapat terlihat pada gambar 4.

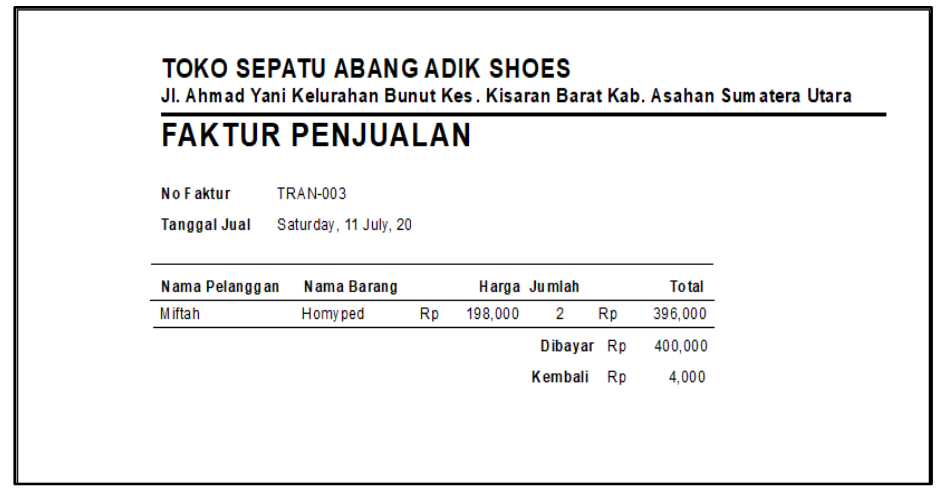

Gambar 4. Laporan Data Penjualan

Kemudian laporan data back order, laporan back order ini akan menampilkan data back order yang dilakukan toko untuk memenuhi kebutuhan pelanggan. Berikut laporan back order terlihat pada gambar 5 .

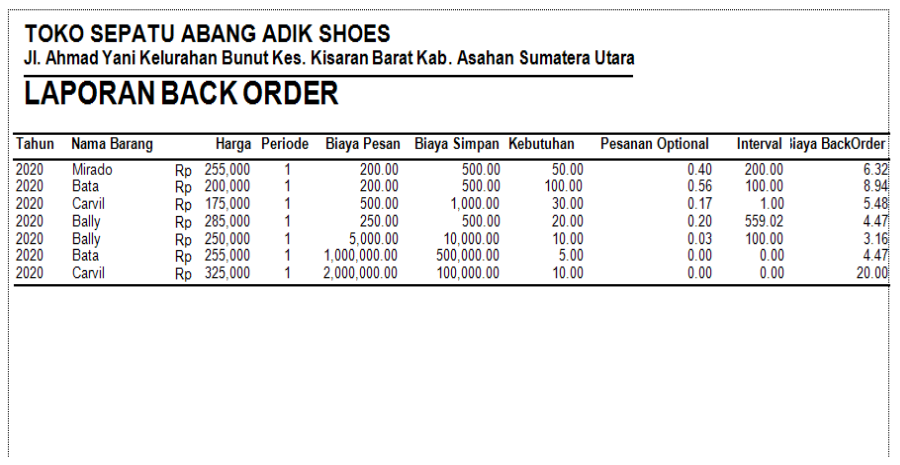

Gambar 5. Laporan Data Back Order

\section{SIMPULAN}

Berdasarkan hasil penelitian dapat disimpulkan bahwa : (1) Dengan adanya sistem stock controlling pada Toko Abang Adik Shoes sehingga perhitungan biayabiaya persediaan lebih akurat. (2), Dengan adanya sistem pengontrolan barang dengan metode back order dapat mencegah terjadinya kekurangan stock barang pada Toko Abang Adik Shoes., (3) Dengan adanya sistem komputerisasi, maka pengerjaan penginputan data barang akan lebih cepat, aman, dan akurat., (4) Dengan adanya sistem ini pimpinan akan mudah melihat data barang yang akan masuk dan yang akan keluar. Peralihan sistem yang ada tidak dilakukan secara mendadak atau langsung, tetapi terlebih dahulu dilakukan penyesuaian antara sistem yang ada selama ini dengan sistem yang baru. Dalam penerimaan karyawan baru harus dilakukan pelatihan supaya tidak terjadi kesalahan dalam melakukan penginputan data barang. 
Vol. 1 No. 2, Juni 2021, hlm. $147-152$

DOI: https://doi.org/10.33330/jutsi.v2i1.1161

Available online at http://jurnal.stmikroyal.ac.id/index.php/jutsi

\section{DAFTAR PUSTAKA}

[1] Y. Ernawati and S. sunarsih, "Sistem Pengendalian Persediaan Model Probabilistik 'Back Order Policy,'” J. Mat. Dan Komput., vol. 11, no. 2, pp. 8793, 2008.

[2] N. P. Novianti, F. Agustina, and R. Marwati, "Peramalan Inventori Optimal Untuk Bahan Baku Menggunakan Metode Probabilistik P Kasus Back Order," J. EurekaMatika, vol. 7, no. 1, pp. 34-46, 2019.

[3] J. Prayoga, "Perancangan Sistem Informasi Pengolahan Data Penjualan Secara Kredit dan Controlling Stock Dengan Menerapkan Metode Backorder Pada Toko Master Menggunakan Bahasa Pemrograman Java dan Database MySql," Algoritm. J. Ilmu Komput. Dan Inform., vol. 3, no. 2, p. 78, 2019, doi: 10.30829/algoritma.v3i2.6439.

[4] E. Aryanny and R. K. Jati, "KAYU PUTIH YANG OPTIMAL DENGAN METODE," vol. 16, no. 01, pp. 106-117, 2021. 